\title{
Gênero, redes e capital social no meio rural: a experiência dos grupos de mulheres no município de São Sepé-RS
}

Gender, networks and social capital in the rural area: the experience of women's groups in the municipality of São Sepé-RS

\section{Claudia Tirelli}

Universidade de Santa Cruz do Sul - UNISC - Santa Cruz do Sul - Rio Grande do Sul - Brasil

\section{Adriana Martini Correa Pedroso}

Universidade de Santa Cruz do Sul - UNISC - Santa Cruz do Sul - Rio Grande do Sul - Brasil

\begin{abstract}
Resumo: O artigo discute os efeitos da participação das mulheres nos grupos de mulheres rurais criados pela EMATER/RS. Busca-se analisar se esta participação tem provocado uma ampliação nas redes de sociabilidade dessas mulheres, de forma a alargar as suas possibilidades de acesso ao capital social e, consequentemente, provocar alterações nos seus modos de vida. A partir da construção de um perfil sócio demográfico das integrantes dos grupos de mulheres no município de São Sepé, e de dados relativos a forma como se dá esta participação nos grupos (tempo, atividades), pôde-se perceber que eles têm proporcionado um maior acesso das mulheres rurais à informações de diferentes naturezas (direitos, serviços públicos, uso de novas tecnologias informacionais), além do reforço dos seus laços de sociabilidade e da ampliação dos seus vínculos com atores externos aos grupos.
\end{abstract}

Palavras-chave: Mulheres rurais. Capital Social. Redes sociais.

Abstract: The article discusses the effects of women's participation in rural women's groups created by EMATER / RS. The aim is to analyze whether this participation has led to an increase in the networks of sociability of these women, in order to widen their possibilities of access to social capital and, consequently, to cause changes in their way of life. Based on the construction of a socio-demographic profile of the women's groups in the municipality of São Sepé, and data on how this participation occurs in groups (time, activities), it can be seen that they have provided a greater Rural women's access to information of different natures (rights, public services, use of new information technologies), as well as the strengthening of their ties of sociability and the extension of their ties with actors external to the groups.

Keywords: Rural women. Share capital. Social networks. 


\section{Introdução}

No Rio Grande do Sul, as ações coletivas de mulheres rurais tiveram início entre as décadas de 60 e 70, período em que as forças modernizadoras provocaram a evasão de muitas famílias do campo para as cidades, em um evidente processo de exclusão social (SCHAAF, 2002). Isso provocou o início da organização política dos agricultores, tendo influenciado na organização dos movimentos participativos de mulheres rurais, inaugurando a sua inserção em espaços antes considerados eminentemente masculinos.

Em anos recentes, as estatísticas de gênero trazidas pelo Censo Demográfico (IBGE, 2014) demonstram que, nos últimos 60 anos, as mulheres têm representado, aproximadamente, 50\% da população rural no Rio Grande do Sul. O trabalho feminino demonstra-se necessário para a produção de alimentos na agricultura familiar e para o desenvolvimento de outras atividades econômicas nas propriedades rurais. Além disso, a presença das mulheres no meio rural tem se mostrado fundamental para a constituição de novas famílias e para a reprodução do modo de vida das comunidades rurais.

Grande parte dos trabalhos desenvolvidos na última década sobre as ações coletivas protagonizadas por mulheres que residem no meio rural tem tido como objeto as lutas sindicais e os movimentos sociais de trabalhadoras rurais, enfatizando as suas ações políticas voltadas a propiciar maior visibilidade para as demandas específicas das mulheres rurais e exigir políticas públicas que respondam às suas necessidades. No entanto, outras formas organizativas existentes no meio rural não têm recebido a mesma atenção por parte da comunidade científica, como é o caso dos grupos de mulheres atuantes nas comunidades rurais. Esses grupos foram criados a partir do trabalho de extensão rural realizado pela EMATER, com o objetivo de levar informações e fomentar novas práticas junto às mulheres das comunidades rurais. Embora inicialmente esses grupos estivessem vinculados a ideia de modernizar o meio rural, interpretado como atrasado, o seu funcionamento foi se alterando ao longo do tempo, incorporando novas pautas e formas de funcionamento. Além disso, os efeitos sociais da participação das mulheres nesses grupos não se restringem somente aos objetivos propostos pelos seus organizadores, na medida em que possibilitam o estabelecimento de novas redes de sociabilidade e de acesso a recursos.

Nesse sentido, o objetivo deste trabalho é analisar de que forma a participação das mulheres nesses grupos possibilitam a alteração das suas redes de sociabilidade e do seu acesso ao capital social, a partir da intensificação das relações entre os próprios moradores locais e da expansão dos vínculos com agentes externos. Através da construção de um perfil sócio demográfico das integrantes dos grupos de mulheres nas comunidades rurais do município de São Sepé, baseado nos resultados da aplicação de um questionário, discutese as suas possibilidades de participação na formação de redes e na produção de capital social.

$\mathrm{O}$ artigo encontra-se estruturado em quatro seções: na primeira seção, recupera-se as principais abordagens sobre o capital social, com ênfase na perspectiva estrutural que sustenta este trabalho; na segunda seção, discute-se as relações de gênero no meio rural, problematizando a implicação dos papéis de gênero para o acesso ao capital social; na terceira seção, apresenta-se o trabalho de extensão rural desenvolvido pela EMATER/RS e, finalmente, na quarta e última seção, expõe-se os resultados da pesquisa sobre o perfil das integrantes dos Grupos de Mulheres no município de São Sepé, associando esses resultados à literatura correlata.

\section{Capital social: um conceito polissêmico}

As discussões em torno do capital social e sua contribuição para os processos de desenvolvimento local e regional, assim como para a sustentação dos regimes democráticos, têm sido recorrentes desde os anos de 1990 no campo das Ciências Sociais, sobretudo a partir da influência da obra de Robert Putnam denominada "Comunidade e Democracia: $A$ 
experiência da Itália Moderna”, publicada em 1993. No mesmo período, também pôde-se observar a rápida difusão e incorporação desse conceito pelas agências e organismos de cooperação internacional, os quais passaram a incentivar ações voltadas à criação e ao fortalecimento das organizações civis como uma via de promoção do desenvolvimento.

No entanto, o conceito de capital social foi concebido bem antes da obra de Putnam e com significados bastante distintos daquele produzido por esse autor.

Segundo Portes (2000), foi a partir da obra de Pierre Bourdieu, ainda nos anos de 1980, que o conceito de capital social passou a receber uma análise mais sistemática, entrando definitivamente na agenda acadêmica internacional. Bourdieu definiu o capital social como "o agregado dos recursos efectivos ou potenciais ligados à posse de uma rede durável de relações mais ou menos institucionalizadas de conhecimento ou reconhecimento mútuo" (BOURDIEU, 1985, apud PORTES, 2000, p. 134).

Segundo Ortiz, na introdução que escreveu à coletânea de Pierre Bourdieu (1983, p.8), a problemática teórica dos escritos deste autor se assenta "sobre a questão da mediação entre o agente social e a sociedade", pois as relações estabelecidas pelos diferentes atores sociais geram disputas na ocupação do espaço no campo social, influenciando no comportamento desses atores, nas estruturas sociais condicionantes e na reprodução de classes. $O$ espaço social é o "campo" onde se manifestam as relações entre os agentes. Desta forma, "o campo se particulariza como um espaço em que se manifestam relações de poder" (BOURDIEU, 1983, p.21), que nada mais são do que as disputas entre os agentes pela propriedade do capital específico valorizado em cada campo. A posição que o agente ocupa dentro do campo vai depender da quantidade de capital que ele possui. Nesse caso, aqueles que possuem maior "quantum social" ocupam posições mais destacadas e detêm maior volume de capital social. Agindo segundo o "habitus" se estabelece uma relação continuada de trocas afetivas, simbólicas ou materiais, individuais e coletivas, proporcionando afirmação e reafirmação dos laços de sociabilidade entre os indivíduos pertencentes a rede, no tempo atual e em continuidade no futuro, o que supostamente se traduz em formas de reprodução do capital social. Por isso Bourdieu (1983, p.73) afirma que habitus é a "mediação universalizante que faz com que as práticas sem razão explícita e sem intenção significante de um agente singular sejam, no entanto, sensatas, razoáveis e objetivamente orquestradas".

Conforme as análises de Portes (2000) e Carpim (2005), o capital social para Bourdieu possui um caráter instrumental, na medida em que funciona como um recurso individual que permite certos acessos sociais através do estabelecimento de relações com outros atores sociais, formando uma rede de contatos e aproximações com reconhecimento simbólico de prestigio, valores e virtudes. Dessa forma, pode ser tratado como um recurso originado nas redes de relações para uso com fins privados, possibilitando que um indivíduo possuidor de um estoque de capital social consiga mobilizar uma extensa rede de relações sociais em proveito de suas intenções "mundanas".

Portanto, se a extensão das redes de relações importa para a produção do capital social, a participação nesta rede de relações sociais daria ao indivíduo acesso a um conjunto de recursos possuídos pelos demais membros da rede: "ser miembro de un grupo proporciona a cada uno de sus miembros todo el soporte del capital poseído colectivamente" (BOURDIEU, 1999, p.14).

Quase uma década depois, a abordagem sobre capital social trazida pelo sociólogo americano James Coleman (1988), amplia os conceitos apresentados por Bourdieu, Coleman dá ênfase à estrutura das relações (normas e regras) e não apenas as relações entre indivíduos. O autor explica o capital social pela sua função, considerando-o como um conjunto de diferentes entidades que compartilham aspectos das estruturas sociais, facilitando as ações de determinados atores sociais. Coleman (1990, apud PUTNAM, 2000, p. 177) afirma 
que "assim como outras formas de capital, o capital social é produtivo, possibilitando a realização de certos objetivos que seriam inalcançáveis se ele não existisse".

Apesar da significativa contribuição das obras de Bourdieu e Coleman para a discussão sociológica sobre capital social, foi a partir dos anos noventa que o termo ganhou maior notoriedade por meio da publicação do livro "Comunidade e Democracia: A experiência da Itália Moderna" (1993), de Roberto Putnam. Este livro tornou-se uma referência para as áreas das Ciências sociais e da Economia, na medida em que atribuía as disparidades de desenvolvimento entre o norte e o sul da Itália, representadas através dos seus indicadores de desenvolvimento econômico e consolidação institucional, às suas diferenças em relação ao capital social, produto da vida associativa construído ao longo da história dessas regiões italianas. Este autor afirma que o contexto cívico é fundamental para o funcionamento das instituições, podendo a cultura cívica atuar positivamente sobre as instituições. As pesquisas de Putnam (2000) apontam que a alta densidade de associações e a existência de relações sociais de reciprocidade são as principais premissas de uma democracia vital e de um engajamento cívico efetivo. Para o autor, as normas de reciprocidade generalizada alimentam um sentimento de confiança, categoria central para o capital social e sua influência sobre o desempenho político e econômico. Tais normas implicam na crença, por parte dos membros participantes da comunidade, de que a existência de um comportamento altruísta contribui para o bem-estar geral e será retribuído no futuro, produzindo resultados passíveis de acumulação para o bem estar particular e da comunidade. São as redes de engajamento cívico que robustecem as normas de reciprocidade, cuja influência produz sanções para aqueles que não retribuem, tornando-se eficazes na medida em que a informação sobre a confiabilidade é comunicada através das redes. O autor afirma, ainda, que a cooperação voluntária depende do capital social, citando, entre outros exemplos, a participação em associações e clubes, pois as regras de reciprocidade entre os membros e os sistemas de participação cívica estimulam a cooperação e a confiança social, reduzindo transgressões e incertezas. Nesse sentido, o autor trata a confiança como um atributo social. De acordo com as suas palavras, "Os estoques de capital social, como confiança, normas e sistemas de participação, tendem a ser cumulativos e a reforçar-se mutuamente. (PUTNAM, 2000, p. 186).

Esta abordagem normativa do capital social produzida por Putnam tem sido alvo de inúmeras críticas desde o final da década de 1990, embora sua utilização ainda seja muito recorrente em estudos sobre desenvolvimento local. Entre as críticas, destacam-se as que apontam para o papel extremamente idealizado que esta perspectiva confere às associações civis. Segundo os críticos, seria necessário investigar que tipos de organizações, sob que circunstâncias e quais os seus efeitos para o sistema político, ao invés de pressupor que a vida associativa em geral produz efeitos positivos para a comunidade e para a vitalidade da democracia (FOLEY e EDWARDS, 1998). Além disso, essa visão do capital social desconsidera as inter-relações entre - Estado e as organizações civis. De acordo com Foley e Edwards (1998), o bom funcionamento da democracia não depende apenas de uma vida associativa pujante, mas da existência de instituições políticas e de uma ordem constitucional que estruture as relações entre elas. Na mesma linha, considera-se que a criação de várias associações, assim como as suas formas de atuação e de organização, só podem ser compreendidas se atentarmos para as relações que estabelecem com os distintos setores do Estado. Por fim, alguns autores (PORTES, 1998; CARPIM, 2005) tem apontado o aspecto tautológico que assume a obra de Putnam, já que seu argumento central sobre o capital social apresenta uma circularidade lógica, na qual os lugares que estão bem governados e progridem economicamente 0 fazem porque têm elevado capital social, o que, por sua vez, produziria maior engajamento cívico e maior estoque de capital social. Produzir-se-iam, dessa forma, círculos virtuosos e, em um sentido inverso, 
círculos viciosos. De acordo com Portes (1998), Putnam não incluiu variáveis que poderiam contestar o seu modelo explicativo nem realizou testes com grupos de controle.

O conceito de capital social que utilizamos neste trabalho baseia-se numa perspectiva relacional, segundo a qual o capital social consiste de recursos que se encontram imersos em redes ou associações e, portanto, não pertencem a nenhum indivíduo tomado isoladamente. Esses recursos valorizados pela sociedade somente podem ser acessados através do estabelecimento de laços diretos e indiretos com outros agentes. Na perspectiva de Lin (2001), as ações promovidas pelos agentes são de duas ordens: expressivas ou instrumentais, sendo as primeiras voltadas à manutenção dos recursos já valorizados, por meio do estabelecimento e do fortalecimento de relações entre indivíduos que ocupam as mesmas posições, e as segundas voltadas à obtenção de recursos valorizados, os quais podem ser alcançados através do estabelecimento de relações com agentes externos ao grupo e que ocupam posições mais favoráveis na estrutura social. De acordo com Carpim (2005, p. 21), nessa perspectiva "o capital social não tem conotação positiva ou negativa, entende-se que pode ser utilizado em diferentes sistemas de trocas para distintas finalidades." Nesse sentido, capital social relaciona-se aos recursos acessados a partir dos vínculos ou relações estabelecidas entre os indivíduos de um espaço social delimitado.

No caso deste trabalho, busca-se analisar se a participação das mulheres rurais nos grupos de mulheres tem possibilitado uma ampliação do seu capital social, através da intensificação dos vínculos estabelecidos entre elas e com agentes externos aos grupos Isso implica em conhecer as interações que se estabelecem no espaço social estudado e apreender concretamente como essas relações permitem (ou não) o acesso à recursos mais valorizados, os quais podem produzir alterações na posição de subalternidade ocupada pelas mulheres do meio rural.

\section{Relações de gênero e as possibilidades de construção de redes no meio rural}

A abordagem da questão de gênero no meio rural se intensificou no Brasil desde o início dos anos de 1980, como resultado do fortalecimento do movimento feminista nacional e internacional, e ao reconhecimento dos direitos das mulheres nas distintas dimensões de suas vidas. (SILVA $E$ SCHNEIDER, 2010, p. 8).

No presente estudo, a questão de gênero refere-se "às diferenças socialmente construídas em atributos e oportunidades associadas com o sexo feminino ou masculino e as interações e relações sociais entre homens e mulheres" (GENDER, 2013, apud IBGE, 2014). É, portanto, um conceito vinculado à valores sociais, que ressaltam as desigualdades vivenciadas pela maioria das mulheres, singularmente no meio rural.

Historicamente, as relações de poder no seio das famílias rurais são fundadas em princípios morais, onde a autoridade do chefe de família se assenta na necessidade de proteção de seus tutelados, neutralizando conflitos e divergências no interior do grupo familiar (SCHAAF, 2001). A autora afirma ainda que esta aparente proteção familiar disfarça relações de dominação e subordinação entre o "chefe de família", na figura do pai em relação à esposa e filhos, pois somente este (o pai de família) desfruta de poder e influência sobre a vida dos demais membros familiares. Mas, para além das relações familiares, outros vínculos formados pelas mulheres nas comunidades rurais também são criados a partir de interesses comuns e como formas de estabelecimento de relações de reciprocidade.

Abordar a implicação dos papéis de gênero para a produção do capital social no meio rural requer uma discussão do modo de vida das mulheres rurais, na medida em que a estrutura social na qual se encontram inseridas constrange as suas possibilidades de participação social e, portanto, do estabelecimento de redes de sociabilidade e de acesso ao capital social. 
Martinez (2010) afirma que as pesquisas sobre mulheres rurais, desenvolvidas a partir dos anos 90, tiveram por objetivo revelar o trabalho feminino nos estabelecimentos agropecuários, salientando a participação das mulheres em tarefas produtivas, e não apenas nas reprodutivas, fenômeno até então desconhecido pela sociologia rural (MARTINEZ, 2010, p. 39).

No meio rural, além dos afazeres domésticos e cuidados com os filhos, muitas mulheres participam do trabalho na produção agrícola, mais comumente o cultivo de hortas e roçados para produção de alimentos para o consumo, bem como as criações e trato dos animais de pequeno porte destinados ao consumo da família (porcos e galinhas entre outros). Estas tarefas não possuem atribuição monetária, sendo considerada uma extensão das atividades domésticas. Trata-se um trabalho "invisível", uma extensa jornada que toma grande parte do tempo em sua rotina diária e que muitas vezes influencia nas suas possibilidades de sociabilização ou participação social, e consequentemente nas oportunidades de acesso ao capital social.

\subsection{Mulheres rurais e processos participativos: a emergência dos movimentos de mulheres rurais}

No Brasil, a emergência dos processos participativos de mulheres trabalhadoras rurais ganhou destaque no final dos anos de 1980, no processo Constituinte, por meio das lutas pela ampliação do direito à seguridade social e a garantia da aposentadoria rural, a qual representou uma forma de distribuição de renda nas comunidades rurais. A partir disso, muitas mulheres rurais conquistaram reconhecimento, embora a efetivação desses direitos seja demorada e não altere imediatamente a relação familiar. De acordo com Faria (2009), os movimentos de mulheres rurais, tais como a Marcha das Margaridas (2000, 2003 e 2007), os acampamentos e mobilizações do Movimento de Mulheres Camponesas (MMC), entre outros, têm alcançado grande capacidade de mobilização no país e conseguido alterar as pautas das políticas públicas no sentido de atender as demandas específicas das mulheres que vivem no meio rural.

Diversos estudos sobre mulheres rurais (SCHAF, 2003; BRUMER, 2004; HEREDIA, 2006; FARIA, 2009; SCHNEIDER, 2010) têm evidenciado a sua condição de trabalhadoras não remuneradas, destacando a situação de desigualdade existente nas relações de gênero estabelecidas no meio rural, que acaba minimizando a importância da participação da mulher nas atividades agrícolas e o seu papel na reprodução social das famílias rurais. Muitas vezes o trabalho feminino é visto como "ajuda" e não como uma atividade essencial à manutenção e reprodução da agricultura familiar. De acordo com Faria (2009, p.24), "a trajetória de luta das mulheres no campo no período recente da história brasileira, desde os anos 1980, mostra a força da reivindicação pelo reconhecimento como trabalhadora e como cidadã."

Heredia (2006) afirma que a luta em torno do reconhecimento da profissão de agricultora (e não de trabalhadora doméstica) esteve na origem dos movimentos de mulheres rurais, os quais visavam romper com a invisibilidade do trabalho feminino na agricultura familiar. A esse respeito, Brumer (2004) afirma que

[...] a posição subordinada das mulheres na esfera produtiva dos estabelecimentos agropecuários é assim evidenciada: i) as tarefas executadas no âmbito da esfera produtiva (produção destinada à comercialização) só são contabilizadas como parte de um esforço coletivo, na maioria das vezes aparecendo apenas como 'ajuda'; ii) seu trabalho na esfera produtiva permanece praticamente invisível, tendo em vista que é praticado no interior do estabelecimento, sendo os homens praticamente os únicos responsáveis pelos contatos com o exterior (contato com extensionistas, bancos, sindicato, cooperativa, firmas vendedoras de insumos e compradores); iii) elas não detêm o conhecimento tecnológico necessário para administrar o estabelecimento agropecuário; iv) elas não administram os recursos originados com a venda da produção. (BRUMER, 2004, p. 211).

Contudo, Heredia (2006) salienta, ainda, que a análise dos movimentos específicos de mulheres rurais que se multiplicaram a partir dos anos noventa, 
com efeitos importantes para o processo de visibilização feminina, também influenciou na construção de políticas públicas destinadas a minimizar a desigualdade de gênero no meio rural. A autora ressalta que a organização e a mobilização das mulheres rurais trouxeram, ao debate público, especialmente aquelas questões relacionadas ao reconhecimento da mulher rural enquanto trabalhadora na agricultura (titulação de terras e demandas de ampliação de direitos trabalhistas e previdenciários). Essas questões relacionadas ao acesso das mulheres rurais à políticas que fortaleçam o seu papel enquanto agricultora têm se tornado tema comum às pautas, bem como o acesso ao crédito e à programas de geração de renda. Estas reinvindicações estão relacionadas a necessidade de reconhecimento social do trabalho da mulher rural. Por isso que, para a autora, os movimentos de mulheres rurais continuam tendo um papel fundamental na efetivação do acesso das mulheres aos direitos conquistados, incentivando mudanças culturais que possibilitem a percepção das mulheres rurais como atoras na esfera social e política.

\section{A EMATER/RS e o trabalho de extensão voltado para os grupos de mulheres rurais}

A fundação da EMATER se deu em 1955, sob a denominação de ASCAR, após a assinatura de um convênio para a criação dos escritórios técnicos de cooperação entre os governos norte-americano e brasileiro. No início dos anos 60 , as famílias e as comunidades rurais eram o foco das ações e a extensão, as quais eram desenvolvidas por um técnico em ciências agrárias e uma funcionária mulher, capacitada a atuar no campo da "economia doméstica". O objetivo da extensão, estabelecido a partir de enfoques teóricos sobre desenvolvimento rural, era diminuir a pobreza rural, vista como decorrência da ignorância e da resistência às mudanças que caracterizariam os agricultores. Do ponto de vista da produção agrícola, o foco estava na conservação do solo e na adoção do crédito rural supervisionado. De forma complementar, as economistas domésticas, através da organização de Grupos do Lar e dos Clubes 4-S, direcionados aos jovens, difundiam conhecimentos sobre saúde, alimentação, saneamento, abastecimento de água, e apoiavam as mulheres nas suas atividades domésticas. (EMATER/RS, 2002; CAPORAL, 2006). De acordo com Caporal (2006), a atuação da ASCAR, até os anos de 1960, se caracteriza pelo assistencialismo e pela aposta no desenvolvimento econômico como propulsor do desenvolvimento social. A seu ver,

\begin{abstract}
Os agentes atuavam com um olho na família e outro na agricultura. O lar e as melhorias nas condições gerais de saúde e bem-estar eram as preocupações centrais dos extensionistas. O crédito rural orientado era uma ferramenta para ajudar nos processos de mudança. A extensão adotava o chamado enfoque clássico. Este enfoque priorizava ações tidas como educativas, cujo objetivo central era melhorar a produção e a produtividade agropecuária, supondo que com isto "naturalmente" se alcançariam melhorias na renda das famílias de modo que estas pudessem ascender a um mais elevado nível de bem-estar (CAPORAL, 2006, p. 2).
\end{abstract}

As mulheres que trabalhavam na extensão rural naquele período não podiam se casar, embora não houvesse uma regra escrita a esse respeito. Esse trabalho era visto quase como um voluntariado e, caso optassem pela formação de uma família, eram convidadas a abandonar o emprego, numa clara discriminação de gênero. Segundo o documento "Marco referencial para as ações sociais da EMATER/RS-ASCAR" (2002), a partir do golpe militar de 1964, as ações de assistência e extensão rural foram restringidas a atendimentos mais individualizados, em geral dirigidos aos 'chefes' das propriedades rurais (homens). De acordo com o documento, as mulheres sequer eram vistas como agricultoras.

Muito embora houvesse restrições, impostas na maioria por parte de integrantes das famílias (maridos, filhos homens mais velhos), os trabalhos de organização de mulheres nos clubes de mães e de senhoras permaneceram, e se transformaram numa marca do trabalho da extensão nos anos 70. Na década seguinte, de 1980 a 1990, assistiu-se à 
reorganização dos movimentos sociais, inclusive no campo, com consequências sobre o trabalho da extensão rural. Ocorreram modificações na forma de prestação dos serviços de assistência técnica e de extensão rural, através da incorporação de metodologias alternativas de trabalho com a agricultura familiar e os pequenos produtores, tendo como foco a organização dos agricultores em associações e conselhos comunitários (Weitzman; Monteiro; Telles; Malerba, 2009). A crítica ao modelo adotado pela Revolução Verde começava a ressoar, sob o ponto de vista ambiental e socioeconômico, com diferenciação social ocorrida no período, pelo empobrecimento de grande parcela da população dedicada à agricultura familiar, resultando em processos crescentes de expulsão da terra, aumento do vínculo de submissão dos agricultores às grandes agroindústrias, mostrando o lado perverso do milagre econômico e da globalização. Neste contexto surgiu o movimento que se propunha a refletir criticamente sobre o papel que a extensão vinha desempenhando nessa realidade, a que se denominou "Repensar da Extensão Rural". Ao mesmo tempo, se multiplicaram as organizações não governamentais (ONGs) e associações no meio rural. (EMATER/RS, 2002). Desde então, "uma diversidade de instituições tem se engajado na implementação de ATER para mulheres, o que também demonstra o alcance da internalização dos novos parâmetros estabelecidos" (WEITZMAN, 2011, p.97), destacando o trabalho da EMATER-RS.

Desde os anos 2000, a extensão rural vem experimentando várias mudanças, com destaque especial para a preocupação com as questões ambientais e para as novas formas de enfrentamento às crises socioeconômicas no meio rural. Em relação às ações sociais, a preocupação com a geração de renda culminou com o desenvolvimento de atividades como agroindústrias, artesanato, turismo rural, entre outras. Intensificaram-se as ações voltadas para a "ecologização" do meio rural, ampliando-se os planos de gestão e educação ambiental, de uso de tecnologias menos agressivas ao meio ambiente, de ações de saneamento básico e ambiental e separação de lixo. Adicionalmente, vem se dando ênfase cada vez maior aos trabalhos de resgate de conhecimentos tradicionais e, em particular, ao trabalho com plantas medicinais, realizado pelas extensionistas de bem estar social.

Nesta sistemática de trabalho, o papel dos profissionais da extensão vem sofrendo importantes mudanças: devem ser mediadores e facilitadores de processos de mobilização e organização de diferentes grupos de interesses e não ser os agentes condutores desses processos. Segundo o documento Marco referencial para as ações sociais da EMATER/RS-ASCAR (2002), as mulheres rurais também tem modificado a sua atuação, através da busca de uma maior autonomia pessoal e profissional e do questionamento das relações entre os gêneros no meio rural, inclusive da forma como o próprio trabalho de extensão rural as tratou ao longo do tempo.

Atualmente, o trabalho da assistência técnica desenvolvido pela EMATER tem concentrado seus esforços na promoção da equidade de oportunidades para as pessoas que vivem no meio rural, especialmente para as mulheres, minimizando as discriminações entre os gêneros, priorizando o fortalecimento das formas organizativas das mulheres, bem como cooperando "para a inclusão produtiva das mulheres e para o desenvolvimento de habilidades empreendedoras que garantam o seu auto sustento" (EMATER, 2016). De acordo com o documento produzido em 2016 pela EMATER, as suas ações em relação às mulheres visam

[...] contribuir para a participação ativa na construção de políticas públicas voltadas ao atendimento de suas demandas relacionadas ao mercado de trabalho, aos direitos, à autonomia em sua atividade produtiva no meio rural, pela superação da jornada tripla de trabalho com a conquista da qualidade de vida, observando as práticas adequadas à conservação do meio ambiente. (EMATER,2016)

A seguir, veremos qual o perfil das mulheres que integram nove grupos de mulheres atuantes em comunidades rurais do município de São Sepé. 


\section{0 trabalho de extensão da EMATER/RS e os} grupos de mulheres rurais do município de São Sepé

Os grupos de mulheres rurais, instituídos como formas de associações comunitárias, contam atualmente com a parceria de outras organizações locais como mediadoras e facilitadoras nos seus processos de mobilização e organização, em especial o trabalho de extensão rural na área social desenvolvido pela EMATER-RS.

Hoje existem no município de São Sepé 9 (nove) grupos informais de mulheres constituídos, localizados nas comunidades rurais de Vila Block, Cerrito do Ouro, Passo dos Freires, Mata Grande, Juliana, São Rafael, Passo dos Brum, Nossa Senhora das Dores e Rincão dos Brum. Esses grupos reúnem em torno de 200 mulheres, com as quais foi realizada esta pesquisa.

A atuação da EMATER-RS junto aos grupos ocorre de acordo com as demandas trazidas pelas participantes e, conforme 0 documento dessa empresa (EMATER, 2016), este trabalho tem como finalidade reduzir as desigualdades de gênero, de aspectos econômicos e sociais e, principalmente, das imensas "contradições entre o meio rural e o urbano, que deverão ser observadas pelo poder público e pela sociedade". Nas duas últimas décadas a extensão rural vem vivenciando grandes mudanças, com destaque especial para a preocupação com as questões ambientais, assim como para a busca de formas de enfrentamento às crises socioeconômicas e aos seus impactos sobre o meio rural. Em relação às ações sociais, a preocupação com a geração de renda, culminou com o desenvolvimento de atividades como agroindústrias, artesanato, turismo rural, entre outras. (EMATER, 2016).

Nas reuniões mensais desses grupos de mulheres são tratados diferentes temas, principalmente àqueles relacionados a saúde, alimentação, lazer, políticas públicas e saneamento básico. Além dessas questões, também são oferecidas oficinas de artesanato e cursos diversos. Para que as ações sejam desenvolvidas, os grupos contam com a parceria dos seguintes entidades e órgãos públicos: Sindicato dos Trabalhadores Rurais, Sindicato Rural SENAR, Centro de Referência da Assistência Social (CRAS), Secretaria Municipal da Saúde e Secretaria Municipal da Agricultura. Os cursos e palestras também contam com o trabalho voluntário de membros da comunidade local.

\section{1 $O$ perfil das mulheres participantes dos}

\section{Grupos de Mulheres Rurais do município de São Sepé}

Para atender a proposta teórica deste trabalho evidenciou-se a necessidade de conhecer as mulheres que participam dos grupos, a fim de construir um perfil das associações comunitárias voltadas às mulheres do meio rural no município de São Sepé, trazendo informações sobre a sua criação, as ações desenvolvidas e quem são as participantes. Isso é importante para nosso estudo na medida em que facilita a compreensão das dinâmicas de participação e em alguns pontos retoma os resultados de outras pesquisas já realizados no meio rural.

\section{Gráfico 1 - Idade das mulheres rurais participantes dos grupos}

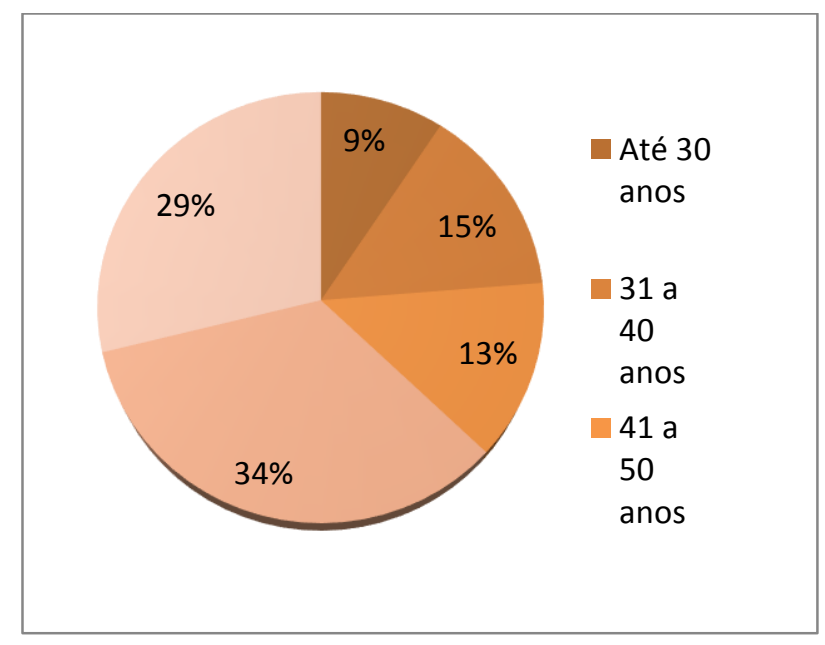

Fonte: Elaborado pelas autoras a partir da análise dos questionários aplicados.

Inicialmente, os dados registrados através das respostas das entrevistadas, sobre a idade das mulheres rurais participantes dos grupos, revelam 
que $63 \%$ das entrevistadas possuem idade superior a 51 anos (34\% com idade entre 51 e 60 anos e $29 \%$ com idade superior a 61 anos). Nesse contexto, os estudos de Sacco Dos Anjos \& Caldas (2008, p. 57) no meio rural, também chamaram a atenção para o "processo generalizado de envelhecimento da população em consequência do duplo impacto provocado pela queda da fecundidade feminina e aumento da expectativa de vida".

\section{Gráfico 2 - Estado Civil das mulheres rurais participantes dos grupos}

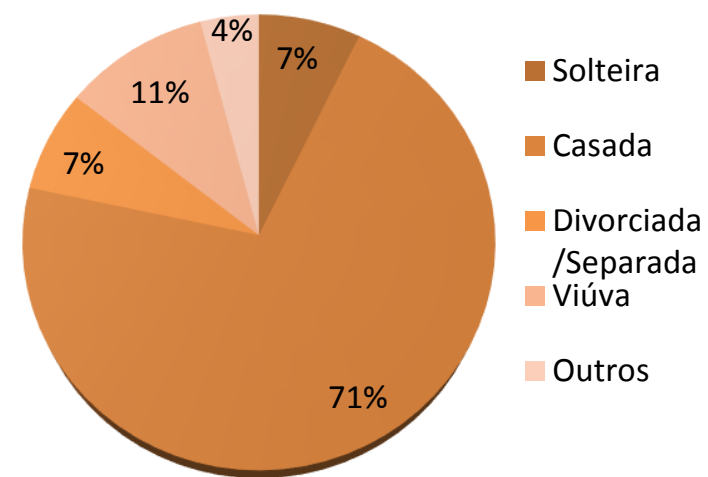

Fonte: Elaborado pelas autoras a partir da análise dos questionários aplicados

Quanto ao estado civil das mulheres participantes dos grupos de mulheres no município de São Sepé, em grande maioria são casadas (71\% das entrevistadas). As mulheres enfrentavam um costume estabelecido desde os primórdios da colonização, que era o recebimento de "dote" no casamento, não recebendo depois os direitos de herança, que eram repartidos com os filhos homens. Assim, o casamento era a única forma de acesso à terra, conforme afirma Paulilo (1998, p.5):

O acesso delas à terra se dá, portanto, principalmente pelo casamento, salvadas as exceções de filhas únicas, ausência de descendência masculina, herança paritária quando há muito o que dividir ou tão pouco que nenhum dos filhos depende do que vai receber ou, ainda, uma ou outra causa igualmente às margens do padrão mais comum.

Os estudos de Melo e Sabatto (2009. p.77) indicam que no meio rural "a posição de chefe na família ainda é tradicionalmente um lugar masculino, e mais recentemente as pesquisas de Zanini e Santos (2013, p.98) apontaram que a "religiosidade católica no interior da unidade familiar camponesa no Rio Grande do Sul é ainda muito importante", confirmando a valorização do casamento formal pelas mulheres rurais, embora também afirmem que 0 campo não está imune às transformações em curso na sociedade. 
Gráfico 3 - Família das mulheres rurais

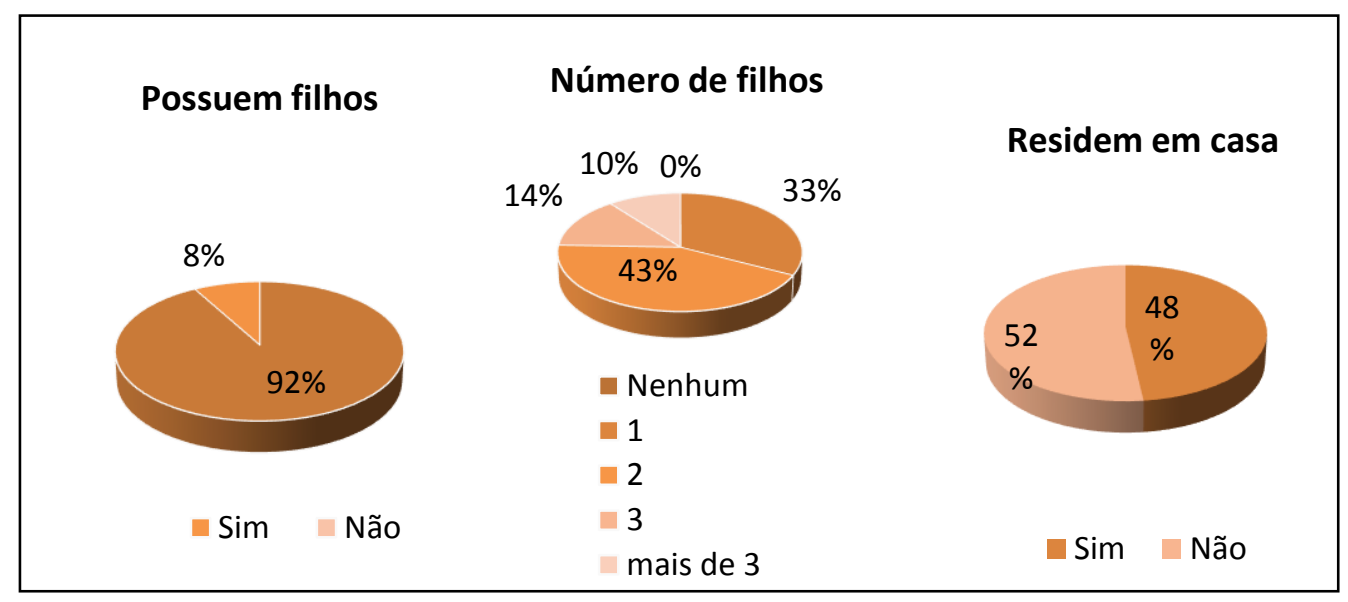

\section{participantes dos grupos}

Fonte: Elaborado pelas autoras a partir da análise dos questionários aplicados.

A maioria das mulheres pesquisadas possuem filhos (92\%). Faria (2009, p. 18) irá dizer que a associação entre casamento e maternidade entre as mulheres do meio rural deve-se a forma pela qual elas desenvolveram a sua identidade primária. A seu ver,

Para as mulheres a realização do trabalho doméstico e de cuidados coloca-se como parte de sua identidade primária, uma vez que a maternidade é considerada seu lugar principal. Essa identidade é introjetada de forma profunda pelas mulheres e sua vivência está marcada pela avaliação das funções maternas e valores associados: a docilidade, fragilidade, compreensão, cuidado, afeto. $\mathrm{Na}$ verdade esse discurso da boa mãe é uma construção ideológica para que as mulheres continuem fazendo o trabalho doméstico.

Por outro lado, as pesquisas de Zanini e Santos (2013) afirmam que, na região central do RS, a quantidade de filhos por casais reprodutivos é pequena (entre um ou dois), não havendo intenção em ter mais filhos. Entre as razões apontadas para essa decisão de não criar mais filhos estão os limites financeiros e a sobrecarga do trabalho feminino. Por fim, mais da metade das mulheres entrevistadas relatam que seus filhos não moram mais em casa, seja por que foram morar nos centros urbanos para estudar ou trabalhar ou porque já constituíram novas famílias.

\section{Gráfico 4 - Nível de instrução das mulheres rurais participantes dos grupos}

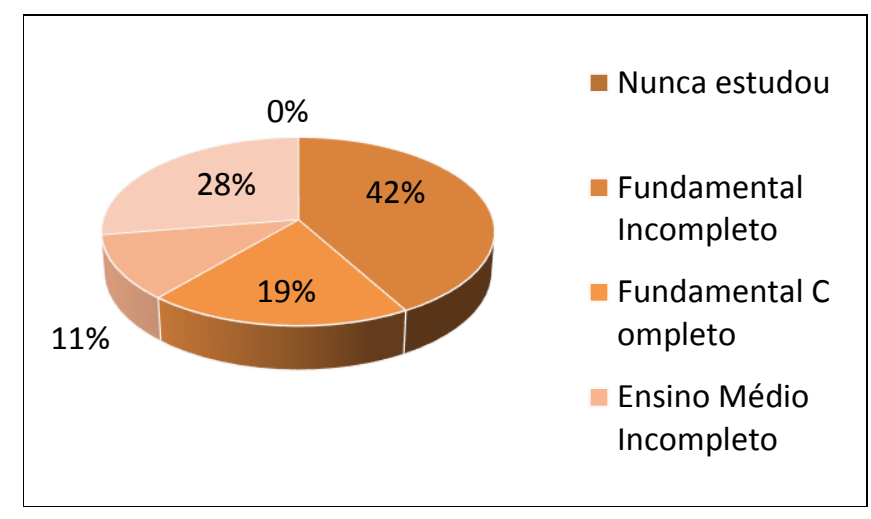

Fonte: Elaborado pelas autoras a partir da análise dos questionários aplicados.

Quanto ao grau de instrução/escolaridade das mulheres pesquisadas, verificou-se que quase metade das mulheres pesquisadas possui ensino fundamental incompleto (42\%). Esse percentual com menor escolaridade reflete a situação das mulheres de mais idade nos grupos. Entende-se que essa é uma questão decisiva no acesso a determinadas tecnologias e a outros conhecimentos de gestão dos negócios, os quais poderiam ser viabilizados caso o nível de escolaridade fosse melhorado. 
Por outro lado, os números revelam um bom percentual de mulheres, entre as mais jovens, com ensino médio incompleto (11\%) e completo (30\%). Também não encontramos mulheres analfabetas participando dos grupos.

Esses índices corroboram as informações nacionais apresentadas nos estudos de Melo e Sabatto (2009, p. 47-48) referindo que "no meio rural o número de pessoas com precária ou nenhuma escolaridade é significativo, embora numa trajetória de queda. As mulheres apresentam-se numa posição um pouco melhor do que os homens".

Gráfico 5 - Inclusão Digital: uso de computador e internet pelas mulheres rurais participantes dos grupos

\section{Uso do computador}

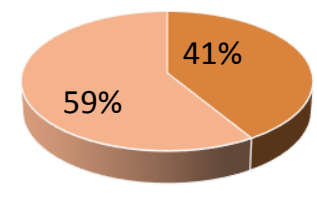

- Sim Não
Tem acesso a internet

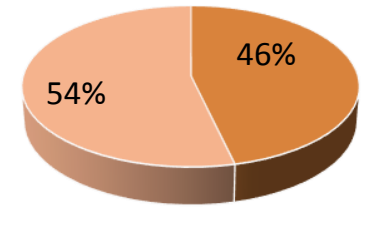

Sim

Não

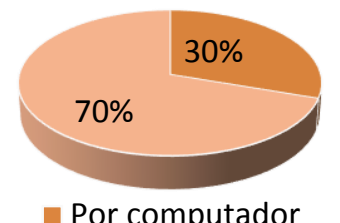

- Por Celular

Fonte: Elaborado pelas autoras a partir da análise dos questionários aplicados.

Em relação à inclusão digital, verifica-se que praticamente a metade do público pesquisado faz uso de computadores, tablets, notebooks, celulares e assemelhados, acessando a internet por computador ou celular. Esses dados indicam que as mulheres rurais também estão fazendo uso das novas tecnologias de comunicação, o que pode vir a contribuir para a intensificação das suas redes de sociabilidade e para o estabelecimento de novas relações. Castells (2005, p.23) afirma que a sociedade em rede transforma os padrões de sociabilidade:

O que nós observamos, não é ao desaparecimento da interação face a face ou ao acréscimo do isolamento das pessoas em frente dos seus computadores. Sabemos, pelos estudos em diferentes sociedades, que a maior parte das vezes os utilizadores de Internet são mais sociáveis, têm mais amigos e contatos e são social e politicamente mais ativos do que os não utilizadores. [...] As pessoas integraram as tecnologias nas suas vidas, ligando a realidade virtual com a virtualidade real, vivendo em várias formas tecnológicas de comunicação, articulando-as conforme as suas necessidades.

\section{Gráfico 4 - Tempo de participação no grupo das} mulheres rurais

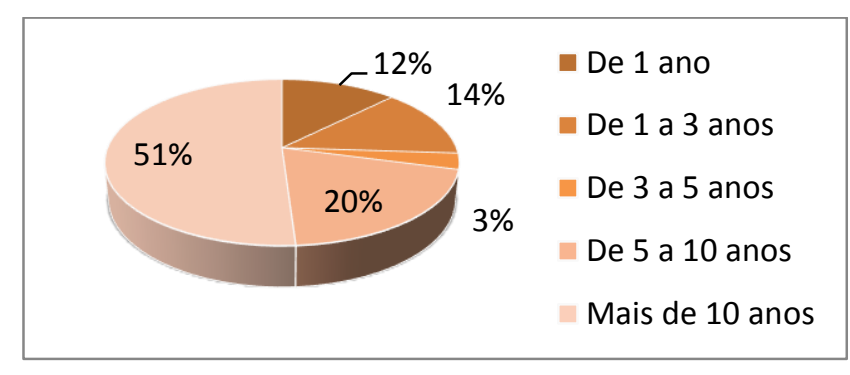

Fonte: Elaborado pelas autoras a partir da análise dos questionários aplicados. 
Mais da metade das mulheres pesquisadas (51\%) participam há mais de 10 anos do grupo, sendo que nos relatos todas verbalizaram que participam desde o início de criação dos grupos. Percebe-se o importante papel de extensão rural realizado pela EMATER-RS, tanto na área técnica quanto na área social, incentivando e apoiando a manutenção desses grupos. De acordo com o depoimento de Auria Reinstein Schroder, Supervisora Regional das equipes técnicas da EMATER-RS,

[...] Precisamos levar o debate e a informação, em temas do cotidiano, do que está acontecendo no entorno maior, além da propriedade e na sociedade como um todo. A mulher só vai se empoderar na hora em que tiver conhecimento e informação, que são condições de agir de igual para igual (grifo nosso).

Lusa (2016, p.246), ao dissertar sobre modos de vida e trabalho rural, afirma que

\begin{abstract}
na dinamicidade da vida cotidiana [..] um traço importante do modo de vida, de trabalho e de produção rural é existência de relações próximas, de confiança e solidariedade, que se manifestam tanto no espaço de trabalho quanto das relações de sociabilidade familiar, de vizinhança e comunitária.
\end{abstract}

Mas para que a "vida associativa" do grupo se mantenha por tanto tempo, essa participação precisa ser interpretada pelas mulheres como sendo produtiva. Daí a necessidade de descobrir empiricamente como a participação dessas mulheres rurais nos grupos tem possibilitado que elas acessem recursos dos quais estariam provavelmente alijadas caso esses não existissem.

\section{Considerações finais}

A partir da abordagem estrutural de capital social adotada neste artigo, pudemos compreender de que forma se estabelecem as redes de sociabilidade feminina no meio rural e como a condição de vida das mulheres atua no sentido de constranger ou possibilitar o seu acesso ao capital social, na medida em que os seus recursos somente podem ser acessados através do estabelecimento de vínculos com outros indivíduos da própria comunidade ou de fora dela. Nesse sentido, pôde-se perceber que os grupos de mulheres têm se constituído como espaços importantes de sociabilidade para as mulheres rurais, posto que grande parte delas participa dos grupos há mais de uma década. O quanto esses grupos tem auxiliado nos seus processos de empoderamento e de busca por uma maior autonomia ainda é uma questão que requer maiores investigações, embora já possam ser observadas pequenas mudanças nas relações de gênero do meio rural, fruto das políticas públicas implementadas nos últimos anos e do reconhecimento gradual das mulheres rurais enquanto agentes fundamentais para a reprodução da pequena propriedade rural baseada na agricultura familiar. O trabalho desenvolvido por meio dos grupos de mulheres, propiciando a intensificação dos vínculos e o estabelecimento de novas relações, certamente tem colaborado para essa mudança.

\section{Referências}

BOURDIEU, Pierre. Sociologia. São Paulo: Ática, 1983.

BRUMER, Anita. Gênero e agricultura: a situação da mulher na agricultura do Rio Grande do Sul. Estudos Feministas, Florianópolis, v. 12, n. 1, p. 205-227, jan/abr. 2004.

BUTTO \& DANTAS et.al. Autonomia e cidadania: políticas de organização produtiva para as mulheres no meio rural / Andrea Butto, Isolda Dantas, orgs. - Brasília: Ministério do Desenvolvimento Agrário, 2011.

CASTELLS, Manuel. A Sociedade em Rede.Do Conhecimento à Acção Política. Org.Manuel Castells e Gustavo Cardoso. Centro Cultural de Belém, 2005.

EMATER 2016. Rio Grande do Sul - ASCAR. Disponível e: http://www.emater.tche.br/

EMATER/RS-ASCAR. Marco referencial para as ações sociais da Série sustentabilidade e Cidadania. Porto Alegre, 2002.

FARIA, Nalu. Economia feminista e agenda de luta das mulheres no meio rural. In: Estatísticas rurais e a economia feminista: um olhar sobre o trabalho das mulheres/ Alberto Di Sabbato; Hildete Pereira de Melo; Maria Rosa Lombardi; 
Nalu Faria; organização de Andrea Butto. Brasília: MDA, 2009.

FOLEY, Michael e EDWARDS, Bob. Beyond Tocqueville: Civil Society and Social Capital in Comparative Perspective. American Behavioral Scientist, 42, 2, September 1998.

HEREDIA, Beatriz M.A e CINTRÃO, Rosângela P. Gênero e acesso a políticas públicas no meio rural brasileiro. In: UNIFEM. O progresso das mulheres no Brasil. Brasília: UNIFEM/ Fundação Ford/CEPIA, 2006.

IBGE. Disponível em <http://www.cidades.ibge.gov.br/painel/historico> . Acesso em 04/09/2016.

LIN, Nan. Social Capital: a Theory of Social Structural and Action, Structural Analysis in the Social Science, Vol. 19, Cambridge: Cambridge University Press.

LUSA, Mailiz Garibotti. Rural: Modos de vida, de Trabalho. In: Dicionário Crítico: Política de Assistência Social no Brasil. Rosa M.C. Fernandes, Aline Hellmann (Org). Porto Alegre, UFRGS, 2016.

MARTINEZ, Rossana Vitelli. Capital social, participação e cidadania no meio rural: uma perspectiva de gênero. 2010. Universidade Federal do Rio Grande do Sul. Instituto de Filosofia e Ciências Humanas. Programa de Pós-Graduação em Sociologia.

MELLO, Hildete Pereira. SABBATO, Alberto Di. Gênero e trabalho rural 1993/2006. In: Estatísticas rurais e a economia feminista: um olhar sobre o trabalho das mulheres/ Alberto Di Sabbato; Hildete Pereira de Melo; Maria Rosa Lombardi; Nalu Faria; organização de Andrea Butto. - Brasília: MDA, 2009.

MORAES, J. L. A. (2003). Capital Social e Desenvolvimento Regional. Capital Social e Desenvolvimento Regional, editado por S. M. D. S. Correa. Santa Cruz do Sul: EDUNISC.

NEVES, Delma Pessanha; MEDEIROS, Leonilde Servolo (Org.). Mulheres camponesas: trabalho produtivo e engajamentos políticos. Niterói: Alternativa, 2013.

PAULILO, Maria Ignez. Terra à vista... e ao longe. $2^{\underline{a}}$ ed.- Florianópolis: UFSC, 1998.

CAPORAL, F. R. Política Nacional de ATER: primeiros passos de sua implementação e alguns obstáculos e desafios a serem enfrentados. In: TAVARES, J. R.; RAMOS, L. (Org.). Assistência Técnica e Extensão Rural: construindo o conhecimento agroecológico. Manaus: IDAM, 2006.
CARPIM, Thaís Regina Pavez. Políticas Públicas e ampliação de capital social em comunidades segregadas: o Programa Santo André Mais Igual. São Paulo, 2005 (Dissertação de Mestrado).

PORTES, Alejandro. Capital social: origens e aplicações na sociologia contemporânea. Sociologia, problemas e práticas, $n . \stackrel{\circ}{3}$, 2000, p. 133-158.

PREFEITURA MUNICIPAL DE SÃO SEPÉ. Disponível em: <www.saosepe.rs.gov.br>. Acesso em 04.09.2016.

PUTNAM, Robert. Comunidade e democracia: a experiência da Itália moderna. Rio de Janeiro: Editora FGV, 2000.

SACCO DOS ANJOS, F. e CALDAS, N.V.O Rural Brasileiro: Velhas e Novas Questões em Debate. In: Teoria \& Pesquisa: Revista de Ciência Política. Jan/Jun 2008. Universidade Federal de São Carlos. Disponível em: $<$ http://www.ppgpol.ufscar.br/>

SCHAAF, Alie Von Der. Jeito de Mulher Rural - A Busca de Direitos Sociais e da Igualdade no RS. Passo Fundo, Editora da Universidade de Passo Fundo, 2001.

SILIPRANDI, Emma. Desafios para a extensão rural: o social na transição agroecológica. Agroecologia e Desenvolvimento Rural Sustentável, v. 3, 2002.

SILVA, C. B. C.; SCHNEIDER, S. Gênero, trabalho rural e pluriatividade. In: SCOTT, P.; CORDEIRO; R.; MENEZES, M. (Org.). Gênero e geração em contextos rurais. Florianópolis: Mulheres, 2010.

WEITZMAN, R.; TELLES, L.; MONTEIRO, S.; MALERBA, J. et. al Relatório Técnico I: Pesquisa sobre a Incorporação de Conceitos, Metodologias e Ferramentas para trabalho com Mulheres e Relações Sociais de Gênero na Política Nacional de Assistência Técnica extensão Rural. Itamaraju- BA: Janeiro, 2009.

WEITZMAN, R Mulheres na assistência técnica e extensão rural. In: Autonomia e cidadania: políticas de organização produtiva para as mulheres no meio rural / Andrea Butto, Isolda Dantas, orgs. - Brasília: Ministério do Desenvolvimento Agrário, 2011.

ZANINI, M. C. C.; SANTOS, M. O. Colonas italianas no sul do Brasil: estigma e identidade. In: NEVES, D. P.; MEDEIROS, L. S. (Org.). Mulheres camponesas: trabalho produtivo e engajamentos políticos. 1ed. Niterói: Alternativa, 2013. 